\title{
Double Stars,
}

\section{Physical Properties \\ and Generic Relations}

Proceedings of IAU Colloquitum No, 80 held at Lembang, Java. 3-7 June 1983

\section{Edited by}

\section{BAMBANG HIDAYAT}

Lembang, Java

ZDENEK KOPAL

Manchester, U.K.

and

JURGEN RAHE

Bamberg, F.R.G.

Reprinted from

Astrophysics and Space Science, Vol. 99, Nos. 1/2

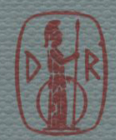

\section{Reidel Publishing Company}

\author{
Dordrecht / Boston
}


DOUBLE STARS, PHYSICAL PROPERTIES AND GENERIC RELATIONS 


\section{Double Stars, \\ Physical Properties \\ and Generic Relations}

Proceedings of IAU Colloquium No. 80 held at Lembang, Java, 3-7 June 1983

Edited by

BAMBANG HIDAYAT

Lembang, Java

ZDENĚK KOPAL

Manchester, U.K.

and

J ÜRGEN RAHE

Bamberg, F.R.G.

Reprinted from

Astrophysics and Space Science, Vol. 99, Nos. 1/2

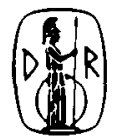

D. Reidel Publishing Company

Dordrecht / Boston 
ISBN 90-277-1748-6

(C) 1984 by D. Reidel Publishing Company, Dordrecht, Holland No part of the material protected by this copyright notice may be reproduced or utilized in any form or by any means, electronic or mechanical including photocopying, recording or by any information storage and retrieval system, without written permission from the copyright owner

Printed in The Netherlands 


\section{TABLE OF CONTENTS}

(Double Stars, Physical Properties and Generic Relations)

BAMBANG HIDAYAT, ZDENĚK KOPAL, and JÜRGEN RAHE / Introduction

ZDENĚK KOPAL / Evolution of Binary Systems and Their Generic Relations. Vainu Bappu Memorial Lecture

J. DOMMANGET / The Importance of Wide-System Studies for Stellar Evolution and Galactic Dynamics

T. HERCZEG / Duplicity on the Main Sequence

HANS ZINNECKER / Binary Statistics and Star Formation

IZUMI HACHISU and YOSHIHARU ERIGUCHI / Fission Sequence and Equilibrium Models of Rigidity Rotating Polytropes

H.-A. OTT / Fission Candidates Among Detached Close Binaries

H. DRECHSEL, W. WARGAU, and J. RAHE / UV Observations of Three Classical Novae during Early Stages of Decline

H. W. DUERBECK / A Catalogue and Finding List of Galactic Novae 93

W. C. SEITTER / The Old Nova BT Monocerotis 95

DAVID A. ALLEN / Symbiotic Stars 101

G. T. BATH / Cataclysmic Variable Stars 127

D. N. DAWANAS and R. HIRATA / Radial Velocity and Profile Variations of the Ultraviolet Circumstellar Lines in $\zeta$ Tauri

W. WARGAU, A. BRUCH, H. DRECHSEL, J. RAHE, and R. SCHOEMBS / Spectroscopy and Optical/IR Photometry of the Cataclysmic Variable CPD- $48^{\circ} 1577$

R. RAJAMOHAN / The H $\alpha$ Line Profile in Early Type-Binary Systems HD 47129 and $\gamma$ Velorum

H. J. BECKER / The Contact Binary AE Phoenicis - An Analysis from Deconvoluted Spectra

CARLSON R. CHAMBLISS / VV Orionis: A Well-Behaved Early-Type Eclipsing Binary System

A. V. RAVEENDRAN / The Light Variability of BD $+25^{\circ} 2511$

BAMBANG HIDAYAT, A. GUNAWAN ADMIRANTO, and KAREL A. VAN DER HUCHT / Wolf-Rayet Binaries: Evolutionary Causes for their Distribution in the Galaxy

DAVID A. H. BUCKLEY / Observations and Models of Some Neglected Southern Eclipsing Binaries

C. DE LOORE / Observations of Binaries and Evolutionary Implications

K. R. RADHAKRISHNAN, M. B. K. SARMA, and K. D. ABHYANKAR/Photometric and Spectroscopic Study of $\mathrm{R} \mathrm{CMa}$

K. C. LEUNG / A Review of Early-Type Close Binary Systems

P. VIVEKANANDA RAO and M. B. K. SARMA / Photometry of the RS CVn Type Eclipsing Binary UV Piscium 
MAMORU SAITŌ, SHUSAKU KAWABATA, KEIICH SAIJO, and HIDEO SATO /

A Spectroscopic Study of Epsilon Aurigae

JON DARIUS / Spectroscopic Segregation in Binary Systems

Y. KONDO, G. E. McCLUSKEY, and S. B. PARSONS / Variable, Optically Thick, Hot Plasma Observed in Interacting Binaries

O. VILHU / Magnetic Braking in Cataclysmic and Low-Mass X-Ray Binaries

J. P. DE GREVE and W. PACKET / Semi-Detached Binaries: The Origin and Present Status of TU Mon, SX Cas, and DM Per

REMO RUFFINI and DOO JONG SONG / Nutational Effects in SS 433

S. FRASCA, F. CIATTI, and A. MAMMANO / Periods Ranging from 5 to 1500 Days in the Anticorrelated Moving Lines of SS 433

C. DE LOORE and W. SUTANTYO / Late Stages of the Evolution of Close Binaries

K. D. ABHYANKAR / Mass Loss in Semi-Detached Binaries

H. W. DUERBECK / Constraints for Cataclysmic Binary Evolution as Derived from Space Distributions

H. J. SCHOBER / A Comparison between Binary Star Light Curves and Those of Possible Binary Asteroids

SATIO HAYAKAWA and MAMORU SAITŌ / Astronomy in Japan

G. SWARUP, B. HIDAYAT, and S. SUKUMAR / Giant Equatorial Radio Telescope

KAREL A. VAN DER HUCHT / A Plan for a New Generation 2 m-Class Telescope in Indonesia

K. C. LEUNG, D. S. ZHAI, R. X. ZHANG, Q. Y. LIU, J. T. ZHANG, and Y. L. YANG / Analysis of 11 Late-Type Close Binary Systems 